Running head: IRT REANALYSIS OF ALLOCENTRIC STRATEGY ITEMS

\title{
A Reanalysis of the Survey-based Navigation Strategy Scale based on Item Response Theory
}

\author{
(version 3.0)
}

Jimmy Y. Zhong ${ }^{1,2}$

${ }^{1}$ School of Psychology, Georgia Institute of Technology, Atlanta, GA 30332, USA

${ }^{2}$ Faculty/School of Arts and Social Sciences, National University of Singapore, Singapore 117570 
IRT REANALYSIS OF ALLOCENTRIC STRATEGY ITEMS

\section{Acknowledgements}

This research was supported by the Graduate Research Support Scheme (GRSS) research grant of the Faculty of Arts and Social Sciences, National University of Singapore (NUS) [Grant ref. no. C581000271511]. Findings were derived from a reanalysis of the published data of Zhong \& Kozhevnikov (2016). I thank Dr. Susan Embretson (Georgia Tech) for her guidance concerning the use of programs for conducting IRT-related analysis and her recommendations for item revision and further assessment. I also thank Drs. Olesya Blazhenkova (Sabanci University) and Maria Kozhevnikov (NUS) for advice on questionnaire design. 


\title{
IRT REANALYSIS OF ALLOCENTRIC STRATEGY ITEMS
}

\author{
Abstract \\ Focusing on 12 allocentric/survey-based strategy items of the Navigation Strategy Questionnaire \\ (Zhong \& Kozhevnikov, 2016), the current study applied item response theory-based analysis to \\ determine whether a bidimensional model could better describe the latent structure of the survey- \\ based strategy. Results from item and model fit diagnostics, categorical response and item \\ information curves showed that an item with the lowest rotated component loading (.27) \\ [SURVEY12], could be considered for exclusion in future studies; and that a bidimensional \\ model with three preference-related items constituting a content factor offered a better \\ representation of the latent structure than a unidimensional model per se. Mean scores from these \\ three items also correlated significantly with a pointing-to-landmarks task to the same relative \\ magnitude as the mean scores from all items, and all items excluding SURVEY12. These \\ findings gave early evidence suggesting that the three preference-related items could constitute a \\ subscale for deriving quick estimates of large-scale allocentric spatial processing in healthy \\ adults in both experimental and clinical settings. Potential cognitive and brain mechanisms were \\ discussed, followed by calls for future studies to gather greater evidence confirming the \\ predictive validity of the full and sub scales, along with the design of new items focusing on \\ environmental familiarity. \\ Keywords: Item response theory, Multidimensional model analysis, Spatial navigation, \\ Allocentric strategy, Questionnaire design
}




\section{IRT REANALYSIS OF ALLOCENTRIC STRATEGY ITEMS}

Navigating to different places is a ubiquitous activity that we conduct in our daily lives.

Previous spatial navigation research has shown that we can encode and retrieve spatial representations of navigable large-scale environments from either a first-person (i.e., egocentric) or third-person (i.e., allocentric) perspective (see, e.g., Blajenkova, Motes, \& Kozhevnikov, 2005; Ishikawa \& Montello, 2006; Taylor \& Tversky, 1996; Zhong, 2011, 2013; Zhong \& Kozhevnikov, 2016; Zhong \& Moffat, 2018). While a first-person/egocentric environmental representation is formed on the basis of one's visuo-perceptual experience and encoding of scenes and activity at the ground-level (Siegal \& White, 1975; Thorndyke \& Goldin, 1983; Werner, Krieg-Brückner, Mallot, Schweizer, \& Freksa, 1997), a third-person/allocentric environmental representation is established based on an imagined external or disembodied vantage point that has been described as being aerial (i.e., a bird's eye view) or schematic in nature (Blajenkova et al., 2005; Münzer \& Hölscher, 2011; Nigro \& Neisser, 1983; Sutton, 2010; Zhong, 2011, 2013; Zhong \& Kozhevnikov, 2016).

In the psychometric literature concerning spatial navigation, there were several notable self-report questionnaires that were designed to assess the strategies that different individuals engage in when they encode and retrieve environmental knowledge from the firstperson/egocentric and third-person/allocentric perspectives. A non-exhaustive list of these questionnaires are: the (a) Wayfinding Strategy Scale (see Lawton, 1994), the (b) Sense of Direction Questionnaire (Kato \& Takeuchi, 2003; see Takeuchi, 1992, for the original version in Japanese), the (c) Questionnaire on Spatial Representation (Pazzaglia \& De Beni, 2001; see Pazzaglia, Cornoldi, \& De Beni, 2000, for the original version in Italian); and more recently, the (d) Navigation Strategy Questionnaire (Zhong, 2013; Zhong \& Kozhevnikov, 2016; see also Zhong, 2011, for the original prototype); the (e) German Questionnaire on Spatial Strategies 
IRT REANALYSIS OF ALLOCENTRIC STRATEGY ITEMS

24 (Münzer, Fehringer, \& Kühl, 2016; see Münzer \& Hölscher, 2011, for the original version in

25 German), and the (f) Wayfinding Questionnaire (van der Ham, Kant, Postma,, \& Visser-Meily, 26 2013).

The current paper focuses on the Navigation Strategy Questionnaire (Zhong, 2013;

Zhong \& Kozhevnikov, 2016), which includes a survey-based (allocentric) strategy scale composed of items that were adapted/modified in relation to conceptually similar items from the first three questionnaires mentioned above (Lawton, 1994; Kato \& Takeuchi, 2003; Pazzaglia \&

De Beni, 2001). Specifically, these survey-based strategy items were designed to assess how well one visualizes environmental features in a schematic third-person/allocentric format and engages the third-person/allocentric perspective when navigating to different destinations. 12 items constituted the scale and they were found to have relatively high interrelatedness (Cronbach's $\alpha$

$35=.86)$, and test-retest reliability $[r(40)=.88]$. Notably, this scale possessed predictive validity with respect to an online/in-situ pointing task that required participants to point to previously observed landmarks/objects immediately after traversing a route that was encountered for the

38 first time (Zhong, 2013; Zhong \& Kozhevnikov, 2016); the mean scale scores correlated moderately with the accuracy scores of this pointing task $[r(500)=.35, p<.01$ (see Table 4 , Zhong \& Kozhevnikov, 2016)]. and validity, it contained one item with a low discriminant loading of .27 [derived from principal

43 component analysis] assessing one's ability to visualize a mental map positioned in a fixed

44 orientation (see last item in Table 1) and three items assessing a selective preference for

\footnotetext{
${ }^{1}$ This is the only behavioral task that correlated significantly with the survey-based strategy scale, and hence the reanalysis of the scale in this paper was conducted in relation to this task only.
} 


\section{IRT REANALYSIS OF ALLOCENTRIC STRATEGY ITEMS}

45 representing environmental knowledge from the third-person/allocentric perspective (see items 3, 4, and 9 in Table 1). The first item was initially designed by Zhong (2013) with reference to

47 classical behavioral studies that implicated the involvement of a disembodied, object-to-object reference system in encoding and retrieving spatial relations between objects/landmarks (Easton \& Sholl, 1995; Rieser, 1989; Sholl, 2001). As for the other three items, they were originally designed to assess one's ability to visualize environmental elements and associated interobject

51 relationships from a third-person/allocentric perspective. Notably, they are exceptional for

52 having the comparative phrase "rather than," which was introduced for the purpose of distinguishing between descriptions of allocentric and egocentric environmental representations

54 (Zhong, 2011, 2013). This wording style was supported by qualitative findings from sketchmaps and interviews suggesting that the fidelity of one's cognitive map could be discerned and distinguished based on whether one engaged a first- or third-person point of view (Blajenkova et

57 al., 2005; Zhong, 2011, 2013; Zhong \& Kozhevnikov, 2016). Critically, these three items differ conceptually from the other nine items, such that they do not conform to traditional notions of

59 navigation strategies as outcome- or goal-oriented (Kato \& Takeuchi, 2003) or as socially contextualized plans of action (Dalton, Hölscher, \& Montello, 2019).

As the discrimination of items assessing survey-based strategy from other items assessing alternative strategy types was done previously using principal component analysis (Zhong, 2011, 2013, Zhong \& Kozhevnikov, 2016), a technique whose quality of findings was largely

64 contingent on the magnitude or regularity of inter-item covariance/correlation (Stevens, 2009),

65 the suitability of each survey-based strategy item was not confirmed with regard to the varying

66 patterns of item responses demonstrated by participants. Therefore, this paper presents a

67 reanalysis of the 12 items of the survey-based strategy scale through item response theory (IRT)- 


\section{IRT REANALYSIS OF ALLOCENTRIC STRATEGY ITEMS}

68 related analysis, which enabled a fine-grained examination of item and component/factor

69 properties by modelling statistical information collected from individual responses to each item

70 (Embretson \& Reise, 2000).

71 The aims of this reanalysis were twofold. First, it aimed to determine whether or not the

72 last item of the scale, which exhibited the lowest component loading among all 12 items, could

73 be considered for exclusion in future studies with regard to item response parameter estimates,

74 item and model level fit indices, and item test information. This aim was set forth in view of the

75 possibility that the poor loading of the last item might have reflected uncertainties associated

76 with assessing one's ability to construct an overview of an environment's layout set in a fixed

77 orientation. Second, the reanalysis aimed to verify if a bidimensional model could better

78 represent the latent structure of the survey-based strategy scale, inasmuch that the three items

79 assessing a selective preference for third-person/allocentric environmental representation could

80 constitute a subscale that associate equally well with online pointing performance as the existing

81 unidimensional scale with 12 items. This aim relates to the possibility that there may exist a

82 component of allocentric/survey-based strategy use that is foremostly concerned with

83 differentiating third-person images from first-person images than with any specific act of

84 navigation. 
IRT REANALYSIS OF ALLOCENTRIC STRATEGY ITEMS

\section{$87 \quad$ Participants}

88

\section{Method}

110 participants (48 females), ranging from 18 to 45 years of age $(M=22.23 ; S D=3.38)$, were recruited from the research participant pool at the National University of Singapore (NUS) for behavioral assessment of spatial knowledge. Based on pre-study screening surveys, these participants had neither studied at the School of Design and Environment (SDE) nor travelled to any places within SDE previously. ${ }^{2}$ They received either modular credits or monetary compensation for their participation. Subsequently, these participants, together with 416 more participants from other departments and schools at NUS, were surveyed online with the Navigation Strategy Questionnaire (NSQ) [Zhong, 2013; Zhong \& Kozhevnikov, 2016]. Survey data from 26 participants were collected after the publication of the questionnaire. ${ }^{3}$

Both the behavioral assessment and the online survey were approved by the institutional review board at NUS. All participants gave consent to participate in the online survey by accepting the terms and conditions stated on an online advertisement posted on the university's intranet. Access to the online survey was provided through a hyperlink on the online advertisement. Archived survey data from three of the initial sample of 110 participants who were tested behaviorally were lost during a file transfer process between computers.

\footnotetext{
${ }^{2}$ Note that these were the same pool of participants reported by Zhong \& Kozhevnikov (2016) in their second study/experiment. The sample size of 110 was determined with respect to a power analysis conducted in that study.

${ }^{3}$ This sample was an add-on to the published data involving 500 survey respondents. This sample size of 500 ensured that each of the original 59 survey items were answered approximately eight times (rounded to the nearest whole number).
} 
IRT REANALYSIS OF ALLOCENTRIC STRATEGY ITEMS

104 Consequently, survey data from a total of 523 participants (254 females) were involved in the 105 data analysis below. They ranged from 18 to 45 years of age $(M=21.98, S D=2.84)$.

107 Procedure ${ }^{4}$

Each of the 107 participants who were recruited for behavioral assessment were led by

the experimenter individually on a route that traversed two floors of the SDE complex (see

111 Figure 1). The route covered approximately 600 meters and took about 10 minutes to traverse. In

112 each experimental session, the experimenter carried a laptop and led the way for one or two

113 participants, who followed him closely behind. Before commencement, the participants were told

114 to remember the configuration of the route and the relative locations of all objects/landmarks

115 they spotted during route traversal and at the route's periphery. Importantly, the experimenter

116 told the participants that they must point to a selection of these landmarks at the end of the route

117 based on a task presented on his laptop. The entrance to the Department of Architecture was

118 selected as the mid-way point (labeled "4", at right side of Figure 1). Once it was reached, the

119 participants were given a short period of rest to inspect and update their memories of the route

120 traveled thus far. Upon arrival at the ending point (see location in Figure 1), all participants

121 performed a pointing task on the experimenter's laptop (see section below). After completion,

122 the participants proceeded to an experimental lab and completed the NSQ online. Their survey

123 data was subsequently merged with the latter pool of 416 respondents for IRT-related analysis of

124 item responses.

\footnotetext{
${ }^{4}$ For a more detailed description of how the route was planned and the purpose of the different route segments depicted in Figure 1, please refer to Zhong (2013) or Zhong \& Kozhevnikov (2016).
} 
IRT REANALYSIS OF ALLOCENTRIC STRATEGY ITEMS

125 Tasks and Materials

126

127

Route-based pointing task. This task was programmed in E-Prime v1.1. and was

128

presented to participants at the end-point of the route. When performing the task, each participant

129

sat facing northwards at a bench and decided on the directions to the landmarks they encountered

130

during route traversal. These landmarks to which they pointed were beyond their line of sight.

131

Although the task was conceived to be assessing participants' ability to retrieve self-to-object

132

relationships that got updated with progression along the route (Zhong, 2013; Zhong \&

133

Kozhevnikov, 2016), it was also designed to assess participants' ability at inferring the spatial

relationships between the route's ending location and the locations of the landmarks/objects they

observed during route traversal, following the assumption that an allocentric mental

representation of one's whereabouts and the relative locations of landmarks would enhance

137 pointing accuracy (Zhong, 2013).

On each trial, the name of an out-of-view landmark was displayed in white on a black

background. A white fixation cross against a black ground separated each trial with a one-second

delay. The participants were instructed to focus their gaze on the screen while doing the task, and

141 to make their responses by pressing one of the four buttons on the number pad (' 1 ', ' 3 ', ' 7 ', and

142 '9'), which had stickers of arrows glued over them. The participants were instructed to press the

143 key that represented the approximate direction to a specified landmark on every trial. The front-

144 left (FL) and front-right (FR) pointing directions were indicated by the buttons '7' and '9'

145 respectively, whereas the back-left $(\mathrm{BL})$ and back-right $(\mathrm{BR})$ pointing directions were indicated

146 by the buttons ' 1 ' and ' 3 ' respectively. To ensure a relatively equal distribution of trials for each

147 pointing direction, three landmarks corresponded to the FR direction, and four landmarks 
IRT REANALYSIS OF ALLOCENTRIC STRATEGY ITEMS

148 corresponded to FL, BL, and BR respectively. On each trial, the name of the target landmark

149 remained on display until a button press was made. Accuracy score (" 1 " for correct and " 0 " for

150 incorrect) and reaction time (i.e., time elapsed from the presentation of each name to the button

151 press, in milliseconds) were recorded with each button press. Each participant performed 15 test

152 trials. These trials presented the names of eight landmarks that were encountered en route to the

153 finishing point and seven landmarks that were located at the periphery of the route. The ordering

154 of the trials followed a randomized sequence.

155

156

Navigation Strategy Questionnaire (NSQ). The online NSQ was created at

157 SurveyTool.com and contained 59 items with 19 items that were specifically designed to assess

158 survey-based navigation strategy (for the complete list of pilot test items, see the appendices of

159 Zhong 2013; Zhong \& Kozhevnikov, 2016). Each participant's responses were registered based

160 on a five-point Likert scale. Ratings at the extremities - " 1 " and " 5 " - were associated with

161 totally disagree and totally agree, respectively while intermediate ratings of " 2 " and " 4 " were

162 associated with disagree and agree, respectively. The rating of " 3 " was associated with a neither

163 agree nor disagree (neutral) response. Before filling up the questionnaire, on-screen instructions

164 informed the participants that the questionnaire concerned different navigational techniques

165 people adopt when they traveled on foot to different places in their everyday environments, and

166 that it was crucial for them to be as honest as possible when rating each statement. Fully

167 completed survey responses were recorded and stored by the online server. Based on principal

168 component analyses that were conducted previously (Zhong, 2013; Zhong \& Kozhevnikov,

169 2016), 12 survey-based strategy items were found to have discriminant component loadings that

170 made them distinct from two other components representing two other types of navigation 


\section{IRT REANALYSIS OF ALLOCENTRIC STRATEGY ITEMS}

171 strategies (egocentric spatial updating and route/procedural); these items were retained to

172 constitute the survey-based strategy scale (see Table 1). Following the present study aims, IRT-

173 related analysis focused on participants' ratings on these 12 items.

174

175 IRT-based Graded Response Model

176

Responses to the 12 survey-based strategy items collected from all 526 respondents were

178 analyzed based on a graded response model (GRM) implemented in IRTPRO v4.1 (Scientific

179 Software International, Inc., Skokie, IL). The GRM is a general framework selected on the basis

180 of a two-parameter logistic (2PL) model that predicts how well a person respond to a particular

181 category of ratings for an item of concern. This model/framework is characterized by the

182 following formula:

$$
P_{i j}=\frac{e^{\alpha_{i}\left(\theta_{s}-\beta_{\mathrm{ij}}\right)}}{1+e^{\alpha_{i}\left(\theta_{s}-\beta_{i j}\right)}}
$$

183 in which

$184 P_{i j}$ Probability of person $s$ endorsing one or more ratings grouped under category $j$ in item $i$

$185 \theta_{s}=$ Trait level of person $s$

$186 \alpha_{i}=$ Item discrimination or slope of item $i$

$187 \beta_{i j}=$ Threshold parameter/value of response category $j$ in item $i$

In this model, as well as in other IRT models, parameters related to person $(\theta)$ and item

$190(\alpha, \beta)$ characteristics are placed on a common scale; and that the logit of $\alpha(\theta-\beta)$ represents a

191 weighted difference score between a person's trait level and an item's category threshold value 


\section{IRT REANALYSIS OF ALLOCENTRIC STRATEGY ITEMS}

192 (Embretson \& Reise, 2000). In the GRM, a large positive difference between these two

193 parametric values means that a person is very likely to endorse a particular response category,

194 which generally contains an assortment of ratings within a specified range.

\section{Results}

\section{GRM Analysis}

To evaluate the item parameter estimates of each survey-based strategy item, a

unidimensional GRM analysis was first performed. Parameter estimation was conducted with the

follows: (i) max. no. of cycles (convergence criterion) $=500$ (0.005); (ii) max. no. of M-step $6.00,6.00)$. In short, this algorithm works by first computing the probability of endorsing a who endorsed that item category at that trait level and the total number of persons who possessed that trait level. Once obtained, the probability/likelihood estimates are maximized over many expectation values in each successive iteration. ${ }^{5}$

\footnotetext{
${ }^{5}$ For more details of the EM algorithm for estimating item parameters in the GRM and other polytomous models, please refer to: Embretson, S. E., \& S., P. Reise (2000). Calibrating Items: Estimation. In Item response theory for psychologists (pp. 187-225). Mahwah, NJ: Lawrence Erlbaum Associates.
} 


\section{IRT REANALYSIS OF ALLOCENTRIC STRATEGY ITEMS}

Table 2 shows the GRM item parameter estimates and the associated communalities and factor loadings for each item. ${ }^{6}$ There were four response categories associated with each item. In ascending order, they were tied to computing the probabilities of endorsing: (i) a rating of " 2 " (disagree) or higher (response category 1), (ii) a rating of "3" (neutral) or higher (response category 2), (iii) a rating of " 4 " (agree) or higher (response category 3), and (iv) a rating of " 5 " (strongly agree) [response category 4]. An examination of the parameter estimates and factor loadings showed that SURVEY12 (When I reconstruct my mental map, its environmental orientation is fixed and does not change with my imagined heading directions) yielded the lowest item discrimination value $(\alpha=0.56)$ and factor loading $\left(\lambda_{u}=.31\right)$, the lowest threshold values in the first $\left(\beta_{1}=-6.41\right)$ and second $\left(\beta_{2}=-1.97\right)$ response categories, and the highest threshold value in the fourth $\left(\beta_{4}=4.62\right)$ response category. The standard errors of these threshold values were also the highest in their corresponding response categories. These parameter estimates attested to the fact that a relatively low percentage of participants endorsed strongly disagree $(3.1 \%)$, disagree $(23.3 \%)$, and strongly agree $(7.8 \%)$.

Further examination of the $S-\chi^{2}$ item level diagnostic statistics (Orlando \& Thissen, 2000) [see Table 3] showed that SURVEY12 stood out for exhibiting the lowest degree of item level fit between the observed data and the predictions of the unidimensional GRM, $\mathrm{S}-\chi^{2}(83)=116.51, p$ $=.009$. An examination of the category response and item information curves (see Figures $2 \&$ 3), further showed that SURVEY12 featured low and irregularly distributed response probabilities in the first and last response categories ( $p s<.10$ for category $0 ; p s<.30$ for category 4), as well as consistently low item information values that were close to zero across the

\footnotetext{
${ }^{6}$ Theta estimates of trait levels were obtained from an assumed/prior normal distribution segmented into 49 gaussian quadrature points (based on default settings)..
} 


\section{IRT REANALYSIS OF ALLOCENTRIC STRATEGY ITEMS}

233 different trait levels $(\min .=0.086, \max .=0.095)$. These item information values are inversely

234 related to the standard errors of the theta estimates; higher information values indicated lower

235 variation in theta/trait levels.

Next, a bidimensional GRM analysis was performed - with three items that were

237 conceived as assessing a selective preference for third-person/allocentric environmental

238 representation (SURVEY03, SURVEY04, and SURVEY09, see Table 1) classified as

239 constituting a content/specific factor. This subfactor represented a subdomain of the

240 central/general factor that comprised all 12 items; cross-loadings on both the general and specific

241 factors were specified with regard to the three preference-related items only. Parameter

242 estimation was conducted with the Bock-Atkin EM algorithm using the same configurational

243 settings as those mentioned in the unidimensional GRM analysis above. Table 4 shows the GRM

244 item parameter estimates and the factor loadings of the central and content factors. The three

245 content factor loadings fell in the moderate range $(.30-.50)$; and two preference-related items

246 (SURVEY03 and SURVEY09) exhibited discrimination estimates on the content factor that

247 were lower than those on the central factor.

In addition, an examination of the likelihood-based goodness of fit indices for overall

249 model fit (see Table 5) showed that the bidimensional model offered a better representation of

250 the latent structure of the item response data than the unidimensional model, $\chi^{2}(3)=39.57, p<$

251.001 (reduction in the value of -2loglikelihood from the unidimensional to the bidimensional

252 model). This finding corresponded well with lower Akaike and Bayesian information criterion

253 values associated with the bidimensional model. With SURVEY12 excluded, the reduction of fit

254 index values from the unidimensional to the bidimensional model occurred at the same relative 
IRT REANALYSIS OF ALLOCENTRIC STRATEGY ITEMS

255 magnitudes, $\chi^{2}(3)=40.92, p<.001$. Noticeably, in each of these two types of model analysis,

256 the exclusion of SURVEY12 led to a relatively large reduction in the model fit index values.

258 Correlational Analysis

259

260

Correlations were performed between the mean scores/ratings of the items constituting the

261 general and content factors, and route-based pointing performance in terms of accuracy and

262 reaction times (natural log transformed). Table 6 shows the descriptive statistics of the variables

263 involved in the correlational analysis. Route-based pointing accuracy was found to correlate

264 moderately and significantly with the mean scale scores obtained from: (i) the full set of 12

265 items; (ii) 11 survey-based strategy items that excluded SURVEY12, and (iii) the three

266 preference-for-allocentric-representation items, $30 \leq r(107) \leq .34$ (see Table 7). The exclusion

267 of SURVEY12 had negligible impact on the magnitude of the correlation (Fisher's $z=0.07, p=$

268 471). It is also worth noting that the mean scale scores obtained from the three preference-

269 related items elicited slightly higher correlation with route-based pointing accuracy $[r(107)=$

$270.34, p<.001]-$ in numerical terms - compared with the correlations obtained from the two other

271 sets of mean scale scores $[r(107)=.31, p=.001($ all 12 items); $r(107)=.30, p<.002(11$

272 items)].

273 To confirm that the significant correlations between the three sets of mean scale scores and

274 route-based pointing accuracy were primarily related to strategic influences, partial correlations

275 were further performed with the effect of sex controlled for. This was because sex correlated

276 significantly with route-based pointing [point-biserial $r(110)=.315, p<.001$ ], with males

277 (coded as “1”) exhibiting higher accuracy scores than females (“0”). After controlling for the 


\section{IRT REANALYSIS OF ALLOCENTRIC STRATEGY ITEMS}

278 extraneous effect of sex, the patterns of significant correlations found previously between the

279 mean scale scores and route-based pointing accuracy remained, albeit with slightly lower

280 correlational values: $.21 \leq r(104) \leq .28$ (see Table 8). Like the earlier findings the exclusion of

281 SURVEY12 had negligible impact on the magnitude of the partial correlation (Fisher's $z=0.07$,

$282 p=.473)$. The mean scale scores obtained from the three preference-related items elicited

283 slightly higher correlation with route-based pointing accuracy $[r(104)=.28, p=.004]$ compared

284 with the correlations obtained from the two other sets of mean scale scores $[r(104)=.22, p=$

$285.024(12$ items $) ; r(104)=.21, p=.031(11$ items $)]$.

286 To ascertain that the normality assumption of Pearson's correlation was met, tests of

287 normality were performed on the standardized residuals emanating from linear regressions

288 corresponding to the bivariate correlations shown in Tables 7 and 8. Joint assessments of Q-Q

289 plots and normality test statistics showed that none of these distributions of residuals deviated

290 significantly from normality with alpha set at $.05(053 \leq$ Kolmogorov-Smirnov's $D \leq, .076, .154$

$291 \leq p \leq .200 ; .981 \leq$ Shapiro-Wilk’s $W \leq .990, .119 \leq p \leq .597)$. 
IRT REANALYSIS OF ALLOCENTRIC STRATEGY ITEMS

Discussion

\section{Summary of Findings and Study Limitations}

Based on a reanalysis of the survey-based strategy items through IRT, the current findings rendered a clearer picture of their psychometric properties. Two major findings emerged: (i) the last item constituting the scale, SURVEY12, exhibited low levels of item fit, category response probabilities, and item information; and (ii) a bidimensional model with three preference-forallocentric-representation items loading on a content factor offered a better representation of the latent structure of the observed data compared to a unidimensional model that represented survey-based strategy as a singular cognitive construct. In view of the IRT-based findings generated by the GRM analysis, researchers administering the survey-based navigation strategy scale can consider omitting it in future studies. Note, however, that this omission is not mandatory as SURVEY12 may still carry conceptual merit when administered to professional 306 navigators working in non-university settings. as a standalone item, or together with other types

307 of strategy items, so any consideration for exclusion should be exercised with a clear purview of 308 research aims. On the other hand, the significant and moderate correlations observed between 309 pointing accuracy and the three preference-related items provided the first set of evidence 310 suggesting that these items might constitute a subscale assessing a specific component of the 311 survey-based strategy. To my knowledge, it is currently unknown as to the mechanisms linking 312 subjective perception of allocentric/survey-based strategy use to spatial navigation or orientation 313 activity and henceforth, I argue that these three preference-related items are related to a decision314 making aspect of survey-based strategy use that requires a comparison of environmental 


\section{IRT REANALYSIS OF ALLOCENTRIC STRATEGY ITEMS}

315 information (either retrieved or computed) from the vantage points of allocentric and egocentric

316 reference frames (see Klatzky, 1998, Mou, McNamara, Valiquette, \& Rump, 2004, for

317 conceptual frameworks of spatial reference frames/systems). This interpretation relates well to

318 the presentation of "rather than" in all three items, which might have compelled participants to

319 take a clear stance (between two imagined viewpoints) on their self-perceived ability to generate

320 allocentric environmental representations. As the current study did not involve substantial

321 cognitive-behavioral testing, this possibility needs verification in future studies, preferably with

322 respect to navigational tasks that assess one's ability to switch between egocentric and

323 allocentric perspectives (see, e.g., Harris \& Wolbers, 2014). This is important because the

324 current proposal of these three items as constituting a subscale can only be confirmed with

325 respect to more spatial navigation tasks in addition to the route-based pointing task.

\section{Potential Brain Mechanisms}

Crucially, the argument for the existence of this subscale aligns well with existing theories

329 and numerous behavioral findings suggesting that the processing and long-term storage of

330 environmental information can occur spontaneously through the use of allocentric reference

331 frames (Blajenkova et al., 2005; Gramann, 2013; Zhong, 2011, 2013; Zhong \& Kozhevnikov,

332 2016) or in relation to a disembodied/external reference system (Greenauer \& Waller, 2010;

333 McNamara, Rump, \& Werner, 2003; Mou et al., 2004; Zhong \& Kozhevnikov, 2016). Extant

334 neuroscience research in spatial navigation also supports this by showing that a direct acquisition

335 of allocentric spatial knowledge is associated with a network of functional activity spanning

336 across the parietal cortex, the retrosplenial cortex, and the hippocampal formation (Aguirre \&

337 D’Esposito, 1999; Byrne, Becker, \& Burgess, 2007; Gramann et al., 2010; Sherrill et al., 2013, 


\section{IRT REANALYSIS OF ALLOCENTRIC STRATEGY ITEMS}

2015). Interestingly, these regions have been proposed as comprising a "computational core" for processing spatial orientation information (Gramann, 2013). Moreover, within the human entorhinal cortex, head direction cells (Jacobs, Kahana, Ekstrom, Mollison, \& Fried, 2010) and grid cells (Doeller, Barry, \& Burgess, 2010; Jacobs et al., 2013; Stangl et al., 2018) may also play active roles in the implementation of an allocentric reference system that registers regular patterns of spatial movements in the global environment. This attests to findings showing that head direction signals coding for allocentric heading directions or bearings get updated without overt attention to egocentric/landmark cues on the part of the moving agent (Jacobs et al., 2010; Taube et al. 1990a, 1990b) — and that grid cells firing along running directions arranged in a six-fold rotational symmetry engendered a "grid-like" map of body movements and positioning in the global environment (Doeller et al., 2010; Jacobs et al., 2013; Stangl et al., 2018).

\section{Recommendations for Future Research}

To gather more evidence confirming the predictive validity of the proposed three-item subscale, as well as the full scale (12 or 11 items, contingent on the exclusion of the last item), I recommend future studies to employ additional spatial navigation tasks that engages one's capacity for large-scale allocentric spatial processing, as mentioned previously by Zhong \& Kozhevnikov (2016). An exemplary task can be an outdoor sporting activity like orienteering, in which the participants must utilize a map and/or a compass to reach a series of waypoints (in a forest, for instance) within a specified amount of time (see, e.g., Di Tore, 2016; Golden, Levy, Vohra, 1987). As this activity spans across large navigable spaces, one would be obliged to imagine or visualize an overview of the environment in order to reach the waypoints within the 


\section{IRT REANALYSIS OF ALLOCENTRIC STRATEGY ITEMS}

361 shortest time possible. Moreover, to ensure greater accuracy in data recording and analysis,

362 future studies should also consider recording pointing or orientation errors [i.e., the discrepancy

363 between a correct/precomputed directional angle and an observed directional angle (derived from

364 the participant)] in terms of degrees or radians. Such errors would offer a better portrayal of

365 behavioral performance, as well as a larger range of values, compared to that of accuracy scores,

366 for correlational or regression analysis.

367 Furthermore, considering that an optimal retrieval of third-person/allocentric

368 environmental knowledge is inadvertently affected by environmental familiarity, inasmuch that

369 familiar environments will facilitate the retrieval process (Piccardi \& Nori, 2011; Zhong, 2011),

370 it will be interesting for future studies to introduce more survey-based strategy items that queries

371 respondents about how differently they encode and retrieve environmental features from the

372 third-person/allocentric perspective between familiar and unfamiliar environments. An

373 exemplary item can be: "In a place that I traveled to for the first time, I attempt to imagine the

374 shape of the route I traversed from an aerial perspective." What can be investigated is to assess

375 whether these new items will constitute additional content factors in a multidimensional model,

376 and whether these subfactors can exhibit predictive validity with respect to navigational

377 performance across different environments evoking varying levels of familiarity.

378

379 Conclusion

380

Taken together, these recommendations for further investigations will offer us a more nuanced understanding of the survey-based strategy as a multidimensional construct, as well as 


\section{IRT REANALYSIS OF ALLOCENTRIC STRATEGY ITEMS}

384 component strategies. Despite the aforementioned limitations, it must be stated that this is the

first study to date which showed that a small number of self-report items assessing allocentric mental imagery could predict pointing/orientation task performance in a large-scale, real-world environment. Since administering three items assessing a preference for allocentric environmental representation requires minimal effort, future studies aiming at a preliminary assessment of their participants' spatial orientation ability can consider surveying them using these preference-related items.

As an assessment of allocentric mental representation and navigation strategy use necessitates the detection of spatial memory deficits associated with the progression of both normal (Zhong et al., 2017; Zhong \& Moffat, 2016, 2018) and pathological aging (Laczó et al., 2010; 2015; Vlček \& Laczó, 2014), the administration of short surveys on allocentric environmental representation will benefit clinicians or neuropsychologists who aim at obtaining quick estimates of older adults' ability to process allocentric spatial information or memory in environmental space. This suggestion aligns well with the current trend of using navigation/wayfinding questionnaires for assessing navigational complaints or disabilities in older adults/patients (see de Rooij,, Claessen, van der Ham, Post, \& Visser-Meily, 2019). Importantly, such surveys, like the one presented in this paper, should be presented to cognitively intact participants (i.e., individuals with no evidence for cognitive impairment or dementia), and combined with behavioral tasks that specifically evaluate allocentric environmental knowledge (as aforementioned) - so as to ensure confidence with clinical assessment or diagnosis.

Overall, the current findings and recommendations for improvements have taken a small step toward this goal and it is hoped that this study will be the first of many studies to come that 
IRT REANALYSIS OF ALLOCENTRIC STRATEGY ITEMS

407 acknowledge the usefulness of short self-report questionnaires/surveys for assessing allocentric 408 environmental knowledge in human subjects with intact cognition. 


\section{IRT REANALYSIS OF ALLOCENTRIC STRATEGY ITEMS}

409

410

411

412

413

414

415

416

417

418

419

420

421

422

423

424

425

426

427

428

429

\section{References}

Aguirre, G. K., \& D'Esposito, M. (1999). Topographical disorientation: a synthesis and taxonomy. Brain, 122, 1613-1628. https://doi.org/10.1093/brain/122.9.1613

Blajenkova, O., Motes, M. A., \& Kozhevnikov, M. (2005). Individual differences in the representations of novel environments. Journal of Environmental Psychology, 25, 97-109. https://doi.org/10.1016/j.jenvp.2004.12.003

Byrne, P., Becker, S., \& Burgess, N. (2007). Remembering the past and imagining the future: a neural model of spatial memory and imagery. Psychological Review, 114, 340-375. https://doi.org/10.1037/0033-295X.114.2.340

Dalton, R. C., Hölscher, C., \& Montello, D. R. (2019). Wayfinding as a Social Activity. Frontiers in Psychology, 10, 142. https://doi.org/10.3389/fpsyg.2019.00142

de Rooij, N. K., Claessen, M. H. G., van der Ham, I. J., Post, M. W. M., \& Visser-Meily, J. M. A. (2019). The Wayfinding Questionnaire: A clinically useful self-report instrument to identify navigation complaints in stroke patients. Neuropsychological Rehabilitation, 29, 1042-1061. https://doi.org/10.1080/09602011.2017.1347098

Di Tore, P. A. (2016). Spatial navigation cognitive strategies, perspective taking and Special Educational Needs: Re-thinking orienteering sport in complexity. Journal of Physical Education and Sport, 16, 476-480. https://doi.org/10.7752/jpes.2016.02073

Doeller, C. F., Barry, C., \& Burgess, N. (2010). Evidence for grid cells in a human memory network. Nature, 463, 657-661. https://doi.org/10.1038/nature08704 
IRT REANALYSIS OF ALLOCENTRIC STRATEGY ITEMS

430 Easton, R. D., \& Sholl, M. J. (1995). Object-array structure, frames of reference, and retrieval of

431

432

433

434

435

436

437

438

439

440

441

442

443

444

445

446

447

448

449

450

451

452 spatial knowledge. Journal of Experimental Psychology: Learning, Memory and Cognition, 21, 483-500. https://doi.org/10.1037/0278-7393.21.2.483

Embretson, S. E., \& S., P. Reise (2000). Item response theory for psychologists. Mahwah, NJ: Lawrence Erlbaum Associates.

Golden, B. L., Levy, L., \& Vohra, R. (1987). The orienteering problem. Naval Research Logistics, 34, 307-318. https://doi.org/10.1002/1520-6750(198706)34:3<307::AIDNAV3220340302>3.0.CO;2-D

Gramann, K. (2013). Embodiment of spatial reference frames and individual differences in reference frame proclivity. Spatial Cognition \& Computation, 13, 1-25. http://dx.doi.org/10.1080/13875868.2011.589038

Gramann, K., Onton, J., Riccobon, D., Mueller, H. J., Bardins, S., \& Makeig, S. (2010). Human brain dynamics accompanying use of egocentric and allocentric reference frames during navigation. Journal of Cognitive Neuroscience, 22, 2836-2849. https://doi.org/10.1162/jocn.2009.21369

Greenauer, N., \& Waller, D. (2010). Micro-and macroreference frames: Specifying the relations between spatial categories in memory. Journal of Experimental Psychology: Learning, Memory, and Cognition, 36, 938-957. http://dx.doi.org/10.1037/a0019647

Harris, M. A., \& Wolbers, T. (2014). How age-related strategy switching deficits affect wayfinding in complex environments. Neurobiology of Aging, 35, 1095-1102. https://doi.org/10.1016/j.neurobiolaging.2013.10.086

Ishikawa, T., \& Montello, D. R. (2006). Spatial knowledge acquisition from direct experience in the environment: Individual differences in the development of metric knowledge and the 
IRT REANALYSIS OF ALLOCENTRIC STRATEGY ITEMS

453

454

455

456

457

458

459

460

461

462

463

464

465

466

467

468

469

470

471

472

473

474

475

integration of separately learned places. Cognitive Psychology, 52, 93-129.

https://doi.org/10.1016/j.cogpsych.2005.08.003

Jacobs, J., Kahana, M. J., Ekstrom, A. D., Mollison, M. V., \& Fried, I. (2010). A sense of direction in human entorhinal cortex. Proceedings of the National Academy of Sciences, 107, 6487-6492. https://doi.org/10.1073/pnas.0911213107

Jacobs, J., Weidemann, C. T., Miller, J. F., Solway, A., Burke, J. F., Wei, X. X., ... \& Kahana, M. J. (2013). Direct recordings of grid-like neuronal activity in human spatial navigation. Nature Neuroscience, 16, 1188-1190. https://doi.org/10.1038/nn.3466

Kato, Y., \& Takeuchi, Y. (2003). Individual differences in wayfinding strategies. Journal of Environmental Psychology, 23, 171-188. https://doi.org/10.1016/S0272-4944(03)00011-2

Klatzky, R. L. (1998). Allocentric and egocentric spatial representations: definitions, distinctions, and interconnections. In C. Freksa, C. Habel, \& K. F. Wender (Eds.), Spatial Cognition: An interdisciplinary approach to representing and processing spatial knowledge. LNAI, 1404 (pp. 1-17). Berlin Heidelberg New York: Springer. https://doi.org/10.1007/3-540-69342-4_1

Laczó, J., Andel, R., Vyhnalek, M., Vlcek, K., Magerova, H., Varjassyova, A., Tolar, M., \& Hort, J. (2010). Human analogue of the morris water maze for testing subjects at risk of Alzheimer's disease. Neurodegenerative Diseases, 7, 148-152. https://doi.org/10.1159/000289226

Laczó, J., Andel, R., Vyhnalek, M., Matoska, V., Kaplan, V., Nedelska, Z., ... \& Hort, J. (2015). The effect of TOMM40 on spatial navigation in amnestic mild cognitive impairment. Neurobiology of Aging, 36, 2024-2033. https://doi.org/10.1016/j.neurobiolaging.2015.03.004 


\section{IRT REANALYSIS OF ALLOCENTRIC STRATEGY ITEMS}

476 Lawton, C. A. (1994). Gender differences in way-finding strategies: relationship to spatial ability

477

478

479

480

481

482

483

484

485

486

487

488

489

490

491

492

493

494

495

496

497

498 and spatial anxiety. Sex Roles, 30, 765-779. https://doi.org/10.1007/BF01544230

McNamara, T. P., Rump, B., \& Werner, S. (2003). Egocentric and geocentric frames of reference in memory of large-scale space. Psychonomic Bulletin \& Review, 103, 589-595. https://doi.org/10.3758/BF03196519

Mou, W., McNamara, T. P., Valiquette, C. M., \& Rump, B. (2004). Allocentric and egocentric updating of spatial memories. Journal of Experimental Psychology: Learning, Memory, and Cognition, 30, 142-157. http://dx.doi.org/10.1037/0278-7393.30.1.142

Münzer, S., Fehringer, B. C., \& Kühl, T. (2016). Validation of a 3-factor structure of spatial strategies and relations to possession and usage of navigational aids. Journal of Environmental Psychology, 47, 66-78. https://doi.org/10.1016/j.jenvp.2016.04.017

Münzer, S., \& Hölscher, C. (2011). Entwicklung und validierung eines fragebogens zu räumlichen strategien [Development and validation of a self-report measure of spatial orientation]. Diagnostica, 57, 111-125. https://doi.org/10.1026/0012-1924/a000040

Nigro, G., \& Neisser, U. (1983). Point of view in personal memories. Cognitive psychology, 15, 467-482. https://doi.org/10.1016/0010-0285(83)90016-6

Orlando, M., \& Thissen, D. (2000). Likelihood-based item-fit indices for dichotomous item response theory models. Applied Psychological Measurement, 24, 50-64. https://doi.org/10.1177/01466216000241003

Pazzaglia, F., Cornoldi, C., \& De Beni, R. (2000). Differenze individuali nella rappresentazione dello spazio: presentazione di un questionario autovalutativo [[Individual differences in spatial representation: A self-rating questionnaire]]. Giornale Italiano di Psicologia, 3, 241-264. 
IRT REANALYSIS OF ALLOCENTRIC STRATEGY ITEMS

499 Pazzaglia, F., \& De Beni, R. (2001). Strategies of processing spatial information in survey and

500

501

\section{2}

503

504

505

506

507

508

509

510

511

512

513

514

515

516

517

518

519

520 landmark-centred individuals. European Journal of Cognitive Psychology, 13, 493-508. https://doi.org/10.1080/09541440125778

Sherrill, K. R., Chrastil, E. R., Ross, R. S., Erdem, U. M., Hasselmo, M. E., \& Stern, C. E. (2015). Functional connections between optic flow areas and navigationally responsive brain regions during goal-directed navigation. NeuroImage, 118, 386-396. https://doi.org/10.1016/j.neuroimage.2015.06.009

Rieser, J. J. (1989). Access to knowledge of spatial structure at novel points of observation. Journal of Experimental Psychology: Learning, Memory and Cognition, 15, 1157-1165. https://doi.org/10.1037//0278-7393.15.6.1157

Sherrill, K. R., Erdem, U. M., Ross, R. S., Brown, T. I., Hasselmo, M. E., \& Stern, C. E. (2013). Hippocampus and retrosplenial cortex combine path integration signals for successful navigation. The Journal of Neuroscience, 33, 19304-19313. https://doi.org/10.1523/JNEUROSCI.1825-13.2013

Sholl, M. J. (2001). The role of a self-reference system in spatial navigation. In D. R. Montello (Ed.), Spatial information theory: Foundations of geographic information science (pp. 217-232). Berlin, Germany: Springer.

Siegel, A. W., \& White, S. H. (1975). The development of spatial representations of large-scale environments. Advances in Child Development and Behavior, 10, 9-55. https://doi.org/10.1016/S0065-2407(08)60007-5

Stangl, M., Achtzehn, J., Huber, K., Dietrich, C., Tempelmann, C., \& Wolbers, T. (2018). Compromised grid-cell-like representations in old age as a key mechanism to explain age- 


\section{IRT REANALYSIS OF ALLOCENTRIC STRATEGY ITEMS}

521

522

523

524

525

526

527

528

529

530

531

532

533

534

535

536

537

538

539

540

541

related navigational deficits. Current Biology, 28, 1108-1115.

https://doi.org/10.1016/j.cub.2018.02.038

Stevens, J. P. (2009). Applied multivariate statistics for the social sciences. New York: Routledge.

Sutton, J. (2010). Observer perspective and acentred memory: Some puzzles about point of view in personal memory. Philosophical Studies, 148, 27-37. https://doi.org/10.1007/s11098010-9498-z

Takeuchi, Y. (1992). Sense of direction and its relationship with geographical orientation, personality traits and mental ability. Japanese Journal of Educational Psychology, 40, 4753 (in Japanese with English abstract). https://doi.org/10.5926/jjep1953.40.1_47

Taube, J. S., Muller, R. U., \& Ranck, J. B. (1990a). Head-direction cells recorded from the postsubiculum in freely moving rats. I. Description and quantitative analysis. Journal of Neuroscience, 10, 420-435.

Taube, J. S., Muller, R. U., \& Ranck, J. B. (1990b). Head-direction cells recorded from the postsubiculum in freely moving rats. II. Effects of environmental manipulations. Journal of Neuroscience, 10, 436-447.

Taylor, H. A., \& Tversky, B. (1996). Perspective in spatial descriptions. Journal of Memory and Language, 35, 371-391. https://doi.org/10.1006/jmla.1996.0021

Thorndyke, P. W., \& Goldin, S. E. (1983). Spatial learning and reasoning skill. In Spatial Orientation (pp. 195-217). Springer, Boston, MA. https://doi.org/10.1007/978-1-46159325-6_9 


\section{IRT REANALYSIS OF ALLOCENTRIC STRATEGY ITEMS}

542 van der Ham, I. J. M., Kant, N., Postma, A., \& Visser-Meily, J. M. A. (2013). Is navigation

543

544

545

546

547

548

549

550

551

552

553

554

555

556

557

558

559

560

561

562

563 ability a problem in mild stroke patients? Insights from self-reported navigation measures. Journal of Rehabilitation Medicine, 45, 429-433. https://doi.org/10.2340/16501977-1139

Vlček, K., \& Laczó, J. (2014). Neural correlates of spatial navigation changes in mild cognitive impairment and Alzheimer's disease. Frontiers in Behavioral Neuroscience, 8. https://doi.org/10.3389/fnbeh.2014.00089

Werner, S., Krieg-Brückner, B., Mallot, H. A., Schweizer, K., \& Freksa, C. (1997). Spatial cognition: the role of landmark, route, and survey knowledge in human and robot navigation. In M. Jarke, K. Pasedach, \& K. Pohl (Eds.), Informatik '97: Informatik als Innovationsmotor (pp. 41-50). Berlin: Springer.

Zhong, J. Y. (2011). Individual differences in navigational strategies and mental representations of large-scale environments. Honors Thesis, National University of Singapore, Singapore (Call no.: BF21-2011-49). Retrieved from https://www.researchgate.net/publication/303049187_Individual_differences_in_navigatio nal_strategies_and_mental_representations_of_large-scale_environments

Zhong, J. Y. (2013). Three types of environmental representations and individual differences in spatial navigation. Master's Thesis, National University of Singapore, Singapore. Retrieved from http://scholarbank.nus.edu.sg/handle/10635/47243

Zhong, J. Y., \& Kozhevnikov, M. (2016). Relating allocentric and egocentric survey-based representations to the self-reported use of a navigation strategy of egocentric spatial updating. Journal of Environmental Psychology, 46, 154-175.

http://dx.doi.org/10.1016/j.jenvp.2016.04.007 


\section{IRT REANALYSIS OF ALLOCENTRIC STRATEGY ITEMS}

564 Zhong, J. Y., Magnusson, K. R., Swarts, M. E., Clendinen, C. A., Reynolds, N. C., \& Moffat, S. D. (2017). The application of a rodent-based Morris water maze (MWM) protocol to an investigation of age-related differences in human spatial learning. Behavioral Neuroscience, 131, 470-482. http://dx.doi.org/10.1037/bne0000219

568 Zhong, J. Y., \& Moffat, S. D. (2016). Age-related differences in associative learning of 569 landmarks and heading directions in a virtual navigation task. Frontiers in Aging Neuroscience, 8. https://doi.org/10.3389/fnagi.2016.00122

571 Zhong, J. Y., \& Moffat, S. D. (2018). Extrahippocampal contributions to age-related changes in spatial navigation ability. Frontiers in Human Neuroscience, 12. 
IRT REANALYSIS OF ALLOCENTRIC STRATEGY ITEMS

574

575

576

577

578

579

580

581

582

583

584

585

586

587

588

589

590

591

592

593

594

595

596

597

598

599

600

601

602

603

\section{Figure Captions}

Figure 1. Floor plan of the route at School of Design and Environment (SDE) at National University of Singapore (NUS) (not drawn to scale). Black dots numbered from 1 to 5 represent the start of each of five route segments. Dot numbers " 1 " and " 6 " represent the starting and ending locations, respectively. Double arrow heads represent the direction along the first leg of each segment. There were 12 landmarks whose names and locations (designated by white circles) were pointed out to participants in sequence. These 12 landmarks were explicitly mentioned because of their inclusion in an imaginal pointing direction task (not mentioned in this paper due to non-significant correlation between its accuracy scores and the survey-based scale scores). The participants were tested on their spatial knowledge of the relative locations of eight of these 12 landmarks in the route-based pointing task. This pointing task also presented the names of seven more landmarks (not shown) located at the periphery or sidewalks of the route [Source: Figure 1 in Zhong \& Kozhevnikov (2016). Reproduced with permission].

Figure 2. Category response curves of the survey-based strategy items under the graded response model. Theta represents the parameter estimates of the ability or trait levels associated with survey-based strategy use in each response category. The probability distribution of five response categories were illustrated to represent, in ascending ordering, the probabilities of endorsing: (i) a rating of "1" (strongly disagree) [response category 0; in black], (ii) a rating of " 2 " (disagree) or higher (response category 1; in blue), (iii) a rating of "3" (neutral) or higher (response category 2; in green), (iv) a rating of "4" (agree) or higher (response category 3; in red), and (v) a rating of " 5 " (strongly agree) [response category 4; in turquoise]. Positive theta/trait levels were associated with higher probabilities of endorsing higher ratings belonging to response categories 3 and 4.

Figure 3. Item information curves of the survey-based strategy items under the graded response model. Item information values were computed by squaring the inversed values of the standard errors of theta estimates. 
IRT REANALYSIS OF ALLOCENTRIC STRATEGY ITEMS

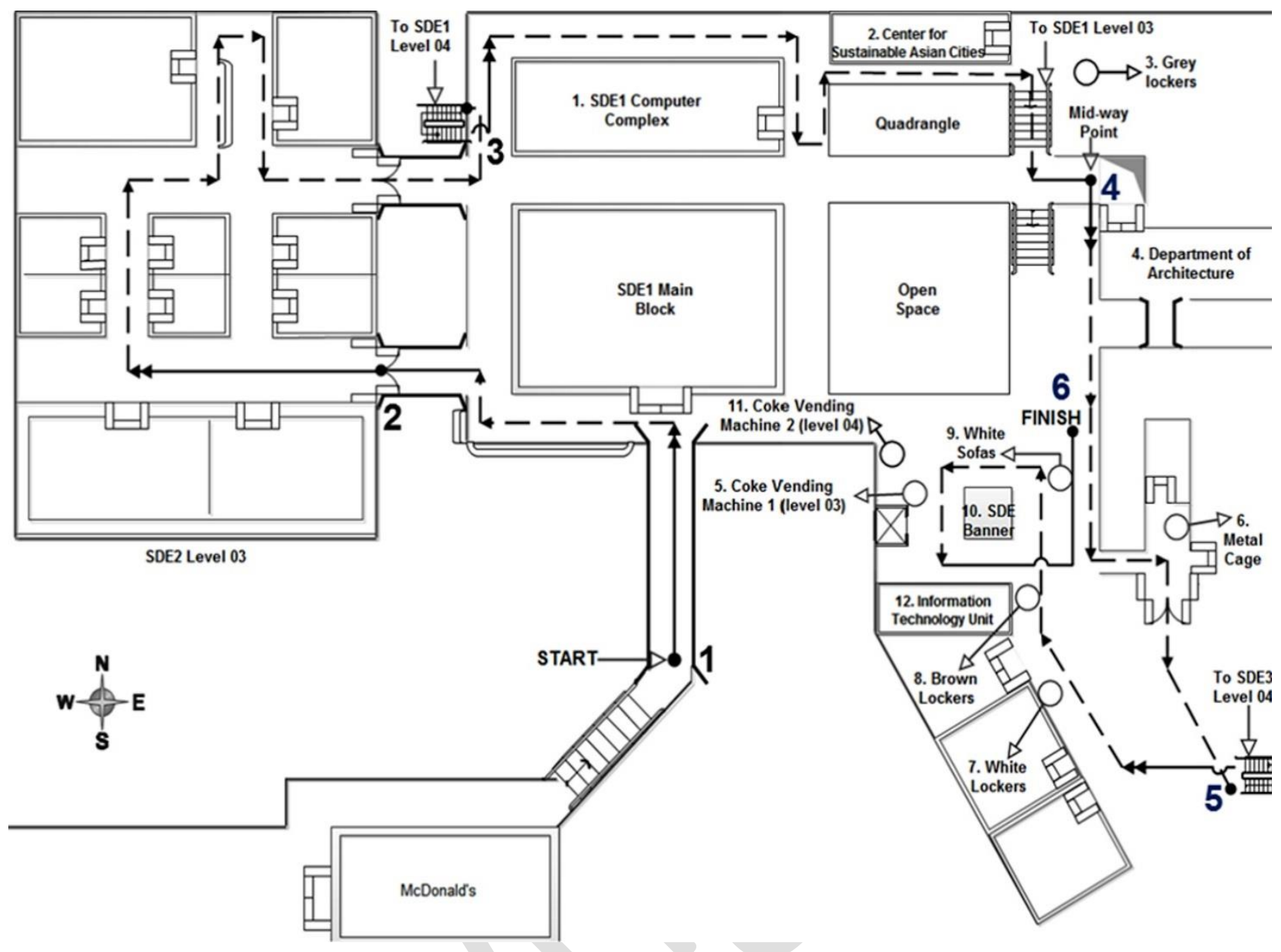


31

ART REANALYSIS OF ALLOCENTRIC STRATEGY ITEMS
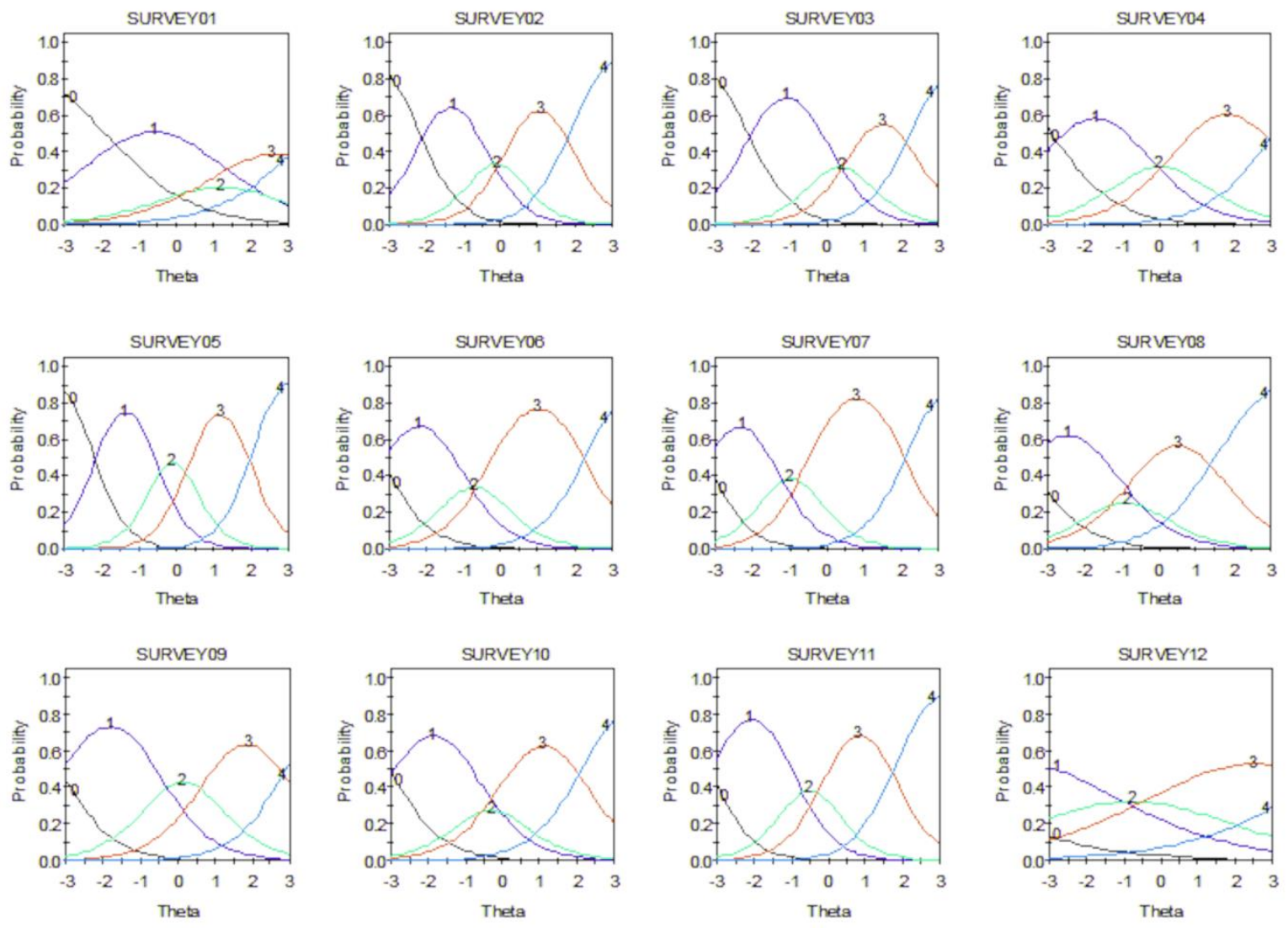

606
607 
32

ART REANALYSIS OF ALLOCENTRIC STRATEGY ITEMS
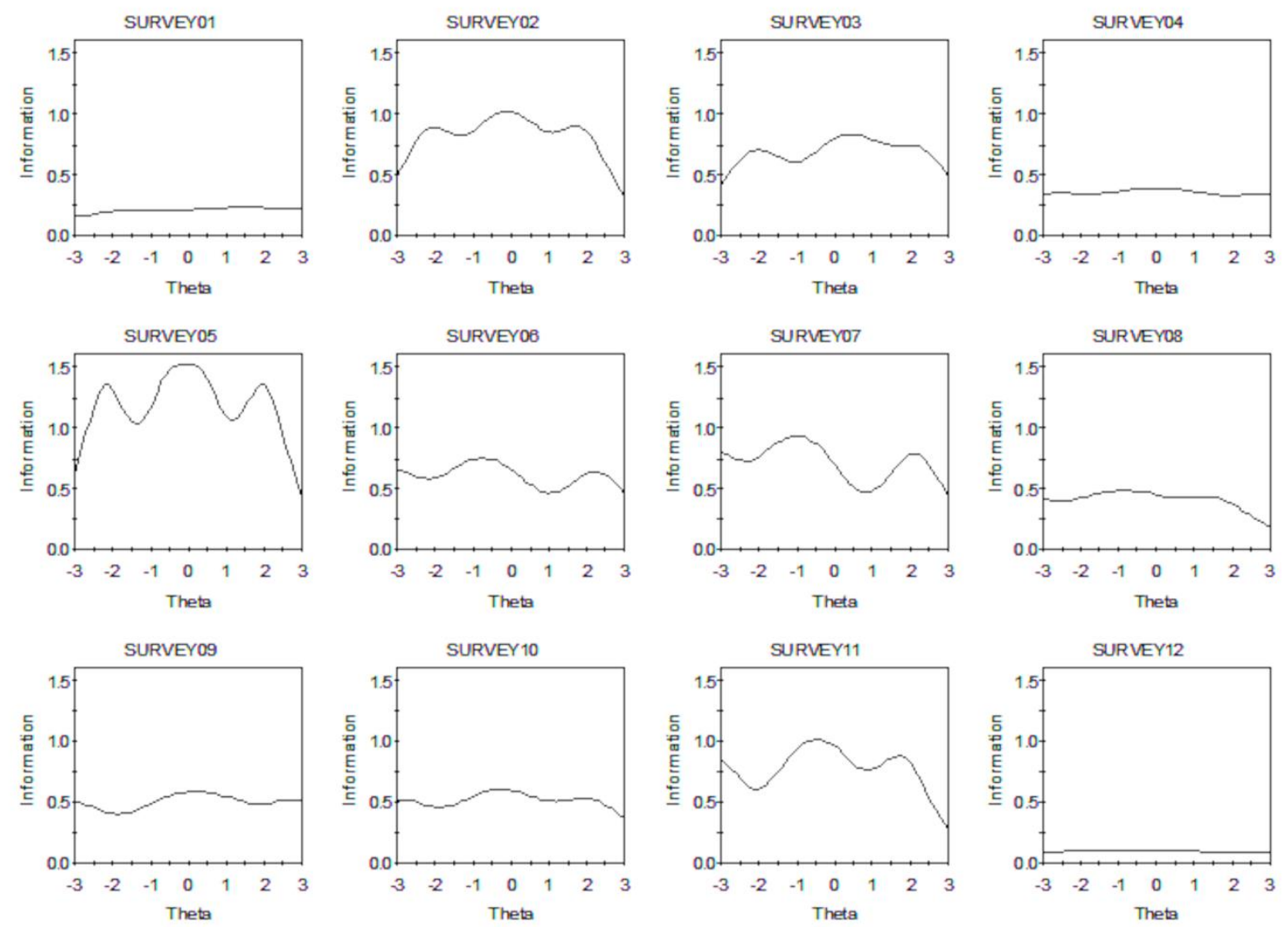

608
609 
IRT REANALYSIS OF ALLOCENTRIC STRATEGY ITEMS

610

611

612

Table 1

Items of the Allocentric/Survey-based Strategy Scale

\begin{tabular}{|c|c|c|}
\hline Item ID & Item & Loading \\
\hline SURVEY01 & $\begin{array}{l}\text { I tend to judge my orientation in the environment in terms of } \\
\text { cardinal directions (north, south, east, west). }\end{array}$ & .40 \\
\hline SURVEY02 & $\begin{array}{l}\text { I usually attempt to visualize a map of the environment from a top- } \\
\text { down aerial perspective as I travel. }\end{array}$ & .62 \\
\hline *SURVEY03 & $\begin{array}{l}\text { My mental representation of the route that I traversed is analogous } \\
\text { to a schematic map (e.g., floor-plan, blue-print, metro map) rather } \\
\text { than a first-person perspective of routes and landmarks. }\end{array}$ & .70 \\
\hline *SURVEY04 & $\begin{array}{l}\text { I tend to reconstruct my traveled route by imagining abstract spatial } \\
\text { relationships amongst different places in a schematic plan rather } \\
\text { than by imagining re-walking the route from a 3D first-person } \\
\text { perspective. }\end{array}$ & .50 \\
\hline SURVEY05 & $\begin{array}{l}\text { I usually attempt to mentally represent route segments, turns and } \\
\text { their spatial relationships from a top-down aerial perspective. }\end{array}$ & .67 \\
\hline SURVEY06 & $\begin{array}{l}\text { I rely primarily on a schematic mental representation of my } \\
\text { environment to help me in finding shortcuts. }\end{array}$ & .60 \\
\hline SURVEY07 & $\begin{array}{l}\text { I rely primarily on a schematic mental representation of my } \\
\text { environment to figure out my position in the environment. }\end{array}$ & .66 \\
\hline SURVEY08 & $\begin{array}{l}\text { I usually rely on a schematic mental representation to orient and } \\
\text { navigate to familiar places. }\end{array}$ & .50 \\
\hline *SURVEY09 & $\begin{array}{l}\text { My mental representation of my traveled route resembles a } \\
\text { schematic plan of abstract spatial relationships rather than a } \\
\text { pictorial, sequential plan of landmarks/objects. }\end{array}$ & .51 \\
\hline SURVEY10 & $\begin{array}{l}\text { When I imagine reorienting myself on my mental map, I tend to } \\
\text { visualize my environment from the top-down aerial perspective and } \\
\text { turn my imagined position to face the new heading. }\end{array}$ & .57 \\
\hline SURVEY11 & $\begin{array}{l}\text { I can plan out my route of travel by visualizing a schematic map } \\
\text { from a top-down aerial perspective. }\end{array}$ & .63 \\
\hline †SURVEY12 & $\begin{array}{l}\text { When I reconstruct my mental map, its environmental orientation is } \\
\text { fixed and does not change with my imagined heading directions. }\end{array}$ & .27 \\
\hline
\end{tabular}

613

614

615

616

617

Note. The loadings pertain to the discriminant loadings on the latent component representing the survey-based strategy [Source: Table 3 in Zhong (2013); Table 2 in Zhong \& Kozhevnikov (2016). Reproduced with permission]. Asterisks denote the three items that were conceived as assessing a selective preference for third-person/allocentric mental representation. " $\uparrow$ " indicates the item that was considered for exclusion in future studies. 
IRT REANALYSIS OF ALLOCENTRIC STRATEGY ITEMS

Table 2

Graded Response Model Item Parameter Estimates and Factor Loadings derived from Unidimensional Analysis

\begin{tabular}{lcccccccccccc}
\hline Item ID & $\alpha$ & $\alpha_{S E}$ & $\beta_{1}$ & $\beta_{S E}$ & $\beta_{2}$ & $\beta_{S E}$ & $\beta_{3}$ & $\beta_{S E}$ & $\beta_{4}$ & $\beta_{S E}$ & $\lambda_{\mathrm{u}}$ & $h_{2}$ \\
\hline SURVEY01 & 0.86 & 0.10 & -1.89 & 0.23 & 0.72 & 0.14 & 1.68 & 0.22 & 3.59 & 0.43 & 0.45 & 0.21 \\
SURVEY02 & 1.84 & 0.16 & -2.16 & 0.16 & -0.49 & 0.07 & 0.26 & 0.07 & 1.84 & 0.15 & 0.73 & 0.54 \\
SURVEY03 & 1.66 & 0.14 & -2.10 & 0.16 & -0.03 & 0.07 & 0.77 & 0.09 & 2.26 & 0.19 & 0.70 & 0.49 \\
SURVEY04 & 1.14 & 0.11 & -2.88 & 0.28 & -0.55 & 0.10 & 0.61 & 0.11 & 3.07 & 0.31 & 0.56 & 0.31 \\
SURVEY05 & 2.30 & 0.20 & -2.19 & 0.15 & -0.52 & 0.07 & 0.36 & 0.07 & 1.99 & 0.15 & 0.80 & 0.64 \\
SURVEY06 & 1.59 & 0.14 & -3.21 & 0.29 & -1.15 & 0.10 & -0.26 & 0.08 & 2.28 & 0.19 & 0.68 & 0.46 \\
SURVEY07 & 1.77 & 0.16 & -3.24 & 0.29 & -1.41 & 0.11 & -0.49 & 0.07 & 2.12 & 0.18 & 0.72 & 0.52 \\
SURVEY08 & 1.27 & 0.12 & -3.61 & 0.36 & -1.31 & 0.13 & -0.50 & 0.09 & 1.51 & 0.16 & 0.60 & 0.36 \\
SURVEY09 & 1.41 & 0.13 & -3.17 & 0.29 & -0.50 & 0.08 & 0.79 & 0.10 & 2.92 & 0.27 & 0.64 & 0.41 \\
SURVEY10 & 1.42 & 0.13 & -3.02 & 0.27 & -0.70 & 0.09 & 0.09 & 0.08 & 2.14 & 0.19 & 0.64 & 0.41 \\
SURVEY11 & 1.84 & 0.16 & -3.17 & 0.28 & -0.94 & 0.09 & -0.06 & 0.07 & 1.76 & 0.14 & 0.74 & 0.55 \\
SURVEY12 & 0.56 & 0.09 & -6.41 & 1.11 & -1.97 & 0.35 & 0.42 & 0.18 & 4.62 & 0.78 & 0.31 & 0.10 \\
\hline
\end{tabular}

Note. Logit: $\alpha(\theta-\beta)$. $\alpha$ : discrimination parameter. $\beta$ : category threshold parameter. $\lambda_{\mathrm{u}}$ : Loadings on the unidimensional factor. $h_{2}$ :

Communality. For each item, the subscript tied to each $\beta$ parameter represents one of four response categories, 
IRT REANALYSIS OF ALLOCENTRIC STRATEGY ITEMS

Table 3

Orlando and Thissen Chi-Square Item Fit Values of the Allocentric/Survey-based Strategy Items

\begin{tabular}{lccc}
\hline Item ID & $S-\chi^{2}$ & $d f$ & $P$ \\
\hline SURVEY01 & 81.79 & 89 & 0.694 \\
SURVEY02 & 80.73 & 72 & 0.225 \\
SURVEY03 & 60.41 & 74 & 0.873 \\
SURVEY04 & 72.01 & 81 & 0.753 \\
SURVEY05 & 60.42 & 61 & 0.498 \\
SURVEY06 & 87.15 & 66 & 0.042 \\
SURVEY07 & 58.67 & 62 & 0.597 \\
SURVEY08 & 83.15 & 74 & 0.218 \\
SURVEY09 & 74.48 & 66 & 0.222 \\
SURVEY10 & 81.01 & 72 & 0.218 \\
SURVEY11 & 60.19 & 62 & 0.542 \\
SURVEY12 & 116.51 & 83 & 0.009 \\
\hline
\end{tabular}


IRT REANALYSIS OF ALLOCENTRIC STRATEGY ITEMS

Table 4

Graded Response Model Item Parameter Estimates and Factor Loadings derived from Bidimensional Model Analysis

\begin{tabular}{lccccccccccccccc}
\hline Item ID & $\alpha_{1}$ & $\alpha_{1 . S E}$ & $\alpha_{2}$ & $\alpha_{2 . S E}$ & $\delta_{1}$ & $\delta_{1 . S E}$ & $\delta_{2}$ & $\delta_{2 . S E}$ & $\delta_{3}$ & $\delta_{3 . S E}$ & $\delta_{4}$ & $\delta_{4 . S E}$ & $\lambda_{1}$ & $\lambda_{2}$ & $h_{2}$ \\
\hline SURVEY01 & 0.84 & 0.10 & - & - & 1.62 & 0.12 & -0.62 & 0.10 & -1.44 & 0.12 & -3.07 & 0.2 & 0.44 & - & 0.20 \\
SURVEY02 & 1.89 & 0.16 & - & - & 4.03 & 0.28 & 0.93 & 0.14 & -0.48 & 0.13 & -3.45 & 0.23 & 0.74 & - & 0.55 \\
SURVEY03 & 1.71 & 0.16 & 0.91 & 0.22 & 3.77 & 0.30 & 0.03 & 0.13 & -1.40 & 0.16 & -4.07 & 0.32 & 0.66 & 0.35 & 0.56 \\
SURVEY04 & 1.22 & 0.15 & 1.22 & 0.29 & 3.87 & 0.36 & 0.74 & 0.14 & -0.87 & 0.15 & -4.11 & 0.39 & 0.50 & 0.50 & 0.50 \\
SURVEY05 & 2.28 & 0.20 & - & - & 5.00 & 0.36 & 1.20 & 0.16 & -0.83 & 0.15 & -4.56 & 0.33 & 0.80 & - & 0.64 \\
SURVEY06 & 1.61 & 0.15 & - & - & 5.11 & 0.38 & 1.84 & 0.15 & 0.43 & 0.12 & -3.64 & 0.25 & 0.69 & - & 0.48 \\
SURVEY07 & 1.80 & 0.16 & - & - & 5.78 & 0.47 & 2.52 & 0.19 & 0.89 & 0.14 & -3.79 & 0.26 & 0.73 & - & 0.54 \\
SURVEY08 & 1.31 & 0.13 & - & - & 4.62 & 0.34 & 1.69 & 0.14 & 0.65 & 0.12 & -1.94 & 0.14 & 0.61 & - & 0.37 \\
SURVEY09 & 1.42 & 0.14 & 0.79 & 0.19 & 4.73 & 0.36 & 0.75 & 0.13 & -1.20 & 0.14 & -4.38 & 0.32 & 0.60 & 0.34 & 0.48 \\
SURVEY10 & 1.46 & 0.13 & - & - & 4.34 & 0.30 & 1.01 & 0.13 & -0.12 & 0.11 & -3.08 & 0.20 & 0.65 & - & 0.43 \\
SURVEY11 & 1.92 & 0.17 & - & - & 5.95 & 0.48 & 1.78 & 0.16 & 0.12 & 0.13 & -3.32 & 0.23 & 0.75 & - & 0.56 \\
SURVEY12 & 0.55 & 0.09 & - & - & 3.57 & 0.26 & 1.10 & 0.10 & -0.23 & 0.09 & -2.57 & 0.17 & 0.31 & - & 0.10 \\
\hline
\end{tabular}

Note. Logit: $\alpha \theta+\delta . \delta=-\alpha \beta . \alpha$ : discrimination parameter. $\beta$ : category threshold parameter. $\lambda_{1}$ : Factor loadings on the central/general factor. $\lambda_{2}$ :

Factor loadings on the content/specific factor. $h_{2}$ : Communality. For each item, the subscript tied to each intercept parameter $(\delta)$ represents one of four response categories. The $\beta$ values tied to each response category and to each dimension can be calculated by dividing $\delta$ by the negative value of $\alpha$. Items without loadings on the content factor did not possess discrimination and category threshold estimates related to the dimension of that factor. 


\section{IRT REANALYSIS OF ALLOCENTRIC STRATEGY ITEMS}

Table 5

Likelihood-based Values and Goodness of Fit Statistics for the Unidimensional and Bidimensional Graded Response Models

\begin{tabular}{lcccc}
\hline Model & -2loglikelihood & $\begin{array}{c}\text { Akaike } \\
\text { Information } \\
\text { Criterion (AIC) }\end{array}$ & $\begin{array}{c}\text { Bayesian } \\
\text { Information } \\
\text { Criterion (BIC) }\end{array}$ & $\begin{array}{c}\text { No. of } \\
\text { Free } \\
\text { Parameters }\end{array}$ \\
\hline Unidimensional (12 items) & 15255.46 & 15375.46 & 15631.38 & 60 \\
Bidimensional (12 items) & 15215.89 & 15341.89 & 15610.61 & 63 \\
Unidimensional (11 items) $^{\mathrm{a}}$ & 13851.90 & 13961.90 & 14196.50 & 55 \\
Bidimensional (11 items) $^{\mathrm{a}}$ & 13810.98 & 13926.98 & 14174.37 & 58 \\
\hline
\end{tabular}

Note. ${ }^{a}$ SURVEY12 excluded. 
IRT REANALYSIS OF ALLOCENTRIC STRATEGY ITEMS

Table 6

Descriptive Statistics of Mean Scale Scores and Pointing Task Performance Measures

\begin{tabular}{lcccc}
\hline Variable & $M$ & $S D$ & Min. & Max. \\
\hline Mean Scale Score (12 items) & 3.21 & 0.71 & 1.50 & 5.00 \\
$\begin{array}{l}\text { Mean Scale Score (11 items; } \\
\text { without SURVEY12) }\end{array}$ & 3.24 & 0.72 & 1.45 & 5.00 \\
$\begin{array}{l}\text { Mean Scale Score (Three } \\
\text { preference-related items) }\end{array}$ & 2.99 & 0.91 & 1.00 & 5.00 \\
$\begin{array}{l}\text { Pointing Accuracy } \\
\text { Pointing Latency (LnRT) }\end{array}$ & 8.33 & 2.91 & 2 & 15 \\
\hline
\end{tabular}

Note. $M=$ Mean, $S D=$ Standard Deviation, Min. = Minimum value, Max. = Maximum value 
IRT REANALYSIS OF ALLOCENTRIC STRATEGY ITEMS

Table 7

Pearson Product-Moment Correlations between Mean Scale Scores and Route-based Pointing Performance

\begin{tabular}{|c|c|c|c|c|c|c|}
\hline & Measure & 1 & 2 & 3 & 4 & 5 \\
\hline 1. & $\begin{array}{l}\text { Mean Scale Score } \\
\text { (12 items) }\end{array}$ & - & $.99 * *$ & $.82 * *$ & $.31 * *$ & -.04 \\
\hline 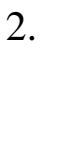 & $\begin{array}{l}\text { Mean Scale Score } \\
\text { (11 items; without } \\
\text { SURVEY12) }\end{array}$ & & - & $.82 * *$ & $.30 * *$ & -.03 \\
\hline 3. & $\begin{array}{l}\text { Mean Scale Score } \\
\text { (Three preference- } \\
\text { related items) }\end{array}$ & & & - & $.34 * *$ & .02 \\
\hline 4. & Pointing Accuracy & & & & & $.19 *$ \\
\hline 5. & $\begin{array}{l}\text { Pointing Latency } \\
(\text { LnRT) }\end{array}$ & & & & & - \\
\hline
\end{tabular}

Note. LnRT: Reaction times (msecs) transformed with natural logarithm.

$* * p<.01$

$* p<.05$ 
IRT REANALYSIS OF ALLOCENTRIC STRATEGY ITEMS

Table 8

Pearson Partial Correlations between Mean Scale Scores Route-based Pointing Performance after controlling for the Effect of Sex

\begin{tabular}{|c|c|c|c|c|c|c|}
\hline & Measure & 1 & 2 & 3 & 4 & 5 \\
\hline 1. & $\begin{array}{l}\text { Mean Scale Score } \\
\text { (12 items) }\end{array}$ & - & $.99 * *$ & $.81 * *$ & $.22 *$ & -.04 \\
\hline 2. & $\begin{array}{l}\text { Mean Scale Score } \\
\text { (11 items; without } \\
\text { SURVEY12) }\end{array}$ & & - & $.80 * *$ & $.21 *$ & -.04 \\
\hline 3. & $\begin{array}{l}\text { Mean Scale Score } \\
\text { (Three preference } \\
\text { related items) }\end{array}$ & & & - & $28 *$ & .01 \\
\hline 4. & Pointing Accuracy & & & & & $.20 *$ \\
\hline 5. & $\begin{array}{l}\text { Pointing Latency } \\
\text { (LnRT) }\end{array}$ & & & & & - \\
\hline
\end{tabular}

Note. LnRT: Reaction times (msecs) transformed with natural logarithm.

$* * p<.01$

$* p<.05$ 